\title{
The investigation of relation between Anxiety and Syndrome Metabolic profiles after 12 Months Aerobic Exercise whit Moderate Intensity in 50-65 Years Old Women with Syndrome Metabolic
}

Ali Osali ( $\square$ osaliphd@bonabu.ac.ir)

Research

Keywords: Aerobic exercise, anxiety, Metabolic syndrome

Posted Date: April 7th, 2020

DOI: https://doi.org/10.21203/rs.3.rs-21135/v1

License: (9) (1) This work is licensed under a Creative Commons Attribution 4.0 International License. Read Full License 


\section{Abstract}

Background and purpose The aim of this research was to investigate the effect of twelve Month aerobic exercise whit moderate intensity on anxiety in 50-65 years old women with syndrome metabolic and relation between anxiety and Syndrome Metabolic profiles.

Materials and methods 24 women with syndrome Metabolic participated voluntarily in this investigation and divided in two-group MetS exercise (ME), MetS control (MC). ME group participated in an aerobic exercise training (AT) program (12 Month), three session per week, each session contained three performing parts and two rest part. Also, Beck anxiety questionnaire and blood samples were conducted before and after training for evaluating levels of anxiety. Data were analyzed using Pried-sample T-Test, Independent samples T-Test, and Pearson correlation.

Results anxiety after 12-month aerobic exercise significantly decreased (Pख0.05), and there was a significant relation between improvement of syndrome metabolic and decreasing of anexiety.

Conclusion These findings indicate that 12-month aerobic exercises induce to decrease anxiety and ameliorate syndrome metabolic. Moreover, we can say ameliorating in Syndrome Metabolic profiles maybe related to decreasing in anxiety levels.

\section{Background}

Aging is an inevitable reality and increasing the elderly population around the world is a matter of attention and it is very important that the World Health Organization has estimated the total number of seniors in 2006 for about 700 millions in the next 40 years and this number will be 2 times in Iran, as well as the population of 60 will be around 10 million years until the year 2020 and 2050 to more than 26 million people (2). Increasing age is associated with increasing the risk of metabolic syndrome (3). Due to change in life style, the prevalence of metabolic syndrome in today's society has increased (4). Metabolic syndrome can have a negative effect on physical performance, mental state, personal, familial and social relationships, and general health and feeling of well-being of patients. Metabolic syndrome was defined according to the criteria of the NCEP/ATP III to include individuals with any three or more of the following five components:(1) Waist circumference > $94 \mathrm{~cm}$; (2) high TG $\geq 150 \mathrm{mg} / \mathrm{dl}$; (3) low HDL-C < $40 \mathrm{mg} / \mathrm{dl}$; (4) high blood pressure (systolic BP $\geq 130 \mathrm{~mm} \mathrm{Hg}$ or diastolic BP $\geq 85 \mathrm{~mm} \mathrm{Hg}$ or treatment of hypertension, and (5) high FBG $\geq 6.1 \mathrm{mmol} / \mathrm{L}(4,5)$ Stress caused by social issues and the absence of a family member leads to increase in anxiety and worry in the person (6). Chronic anxiety and the stress caused by the society cause bulimia and the cause of metabolic syndrome (7). Diseases are the cause of increasing stress and cause anxiety. The results of some fundamental research such as Carroll et al. (2009), and Kai et al. (2015) refers to the positive relationship between anxiety and metabolic syndrome $(8,9)$. In another study, there has been a relationship between anxiety and metabolic syndrome indexes. In particular, they noted a strong relationship between the size of waist cercomfrences, triglyceride and blood pressure (10). While Takeuchi et al. (2009) refers to the presence of a positive and meaningful 
(significantly) relationship between depression and metabolic syndrome and lack of meaningful (significantly) relationship with metabolic syndrome (11). The research of Vogelzangs et al. (2007) noted that anxiety in old men was significantly related to metabolic syndrome, which was not significant in women, and the cause of lack of meaningful (significantly) relationship was related to the impact of the stress which caused by the society which women experience this problem less than men. The question is suggested whether social stress is associated with metabolic syndrome or other variables in that role (12). We will review the research history that has examined the impact of exercise on anxiety reduction. Kargarfard et al. (2011) examined the effect of eight weeks of training on the anxiety of hemophilia patients (13). Salehpoor et al (2015) studied the effect of exercise on the anxiety of young people who had mental disorders (14). Also, Sardari et al. (2009) investigated the effect of 8 weeks of aerobic training on anxiety in patients with type 2 diabetes (15). Given that the previous research has examined the impact of exercise training on anxiety in people with different diseases and so far, there was no research that examined the effect of exercise on anxiety in patients with metabolic syndrome and since the prevalence of metabolic syndrome is much more than other fears. It is a high importance for the research to eliminate the physical and mental problems of these patients.

The aim of this study was to investigate the relationship between metabolic syndrome indices and anxiety of 50-65 year old patients with metabolic syndrome after 12 months of aerobic exercise. Considering that, the origin of stress and anxiety of this participant is a lack of spouse of the martyrs inevitably has been involved with social issues. the martyr's widows have been involved with social issues. According to the results mentioned fundamental research can be said of this process, affecting their stress and anxiety disorder is metabolic syndrome. The question is, in the mind of the researcher, does the choice of exercise reduce the level of anxiety in martyrs' wive and what is the relationship of anxiety with the indicators of metabolic syndrome after 12 months of aerobic exercise? Many studies have examined the effect of aerobic exercise on metabolic syndrome. But so far, research investigating the association of anxiety with metabolic syndrome indices after 12 months of aerobic exercise in women who have lost their spouses for more than 30 years has not been investigated.

\section{Methods}

\section{Participants}

The same-experimental method was applied and the research design consisted of pre-test and post-test with a control group and an experimental group. Forty-four females with metabolic syndrome ages aged 60-65 years participated in this research after giving written informed consent. This research was conducted according to the guidelines laid down in the Declaration of Helsinki and was approved by the ethics committees of Semnan University of Medical Sciences and Health Services (IR.SEMUMS.REC.1396.107). It should be noted that four subjects were excluded from the study due to absence of regular exercise and two control subjects due to absence of post-test. Finally, 24 subjects were included in the statistical analysis. The exclusion criteria for absenteeism were more than three sessions out of twelve sessions. 


\section{Metabolic Syndrome Definition}

Metabolic syndrome was defined according to the criteria of the NCEP/ATP III to include individuals with any three or more of the following five components: (1) Waist circumference $>94 \mathrm{~cm}$; (2) high TG $\geq$ $150 \mathrm{mg} / \mathrm{dl}$; (3) low HDL-C < $40 \mathrm{mg} / \mathrm{dl}$; (4) high blood pressure (systolic BP $\geq 130 \mathrm{~mm} \mathrm{Hg}$ or diastolic BP $\geq$ $85 \mathrm{~mm} \mathrm{Hg}$ or treatment of hypertension, and (5) high FBG $\geq 6.1 \mathrm{mmol} / \mathrm{L}(5)$.

\section{Exercise protocol}

Each subject walked or ran at $65-75 \%$ heart rate reserve (HRR) on a treadmill for 3 $12-17$ min. Over the 12- months treatment, each week, one minute was added to each set, beginning with 8 minutes, so that the duration of each training set at the 12 week was 19 minutes. After the 12 weeks, the training set times did not change. Each session consisted of three sets of consecutive sessions with a 5-minute rest interval between the sets. Heart Rate was monitored during the test using heart rate monitoring devices (Polar M400; Finland).

\section{Measurement of biochemical parameters}

Fasting venous blood samples were taken from the antecubital vein 24 hours before (Fasting blood samples were taken at 9am) and after exercise (It should be noted, however, that in order to eliminate the acute effects of exercise such as delayed fatigue and possible minor damage to muscle structure on blood variables, post-test blood sampling was performed four days after the last training session) (17, 18).

For measuring serum blood markers, the samples were allowed to clot for $30 \mathrm{~min}$ at room temperature and then centrifuged at $3000 \mathrm{rpm}$ for $10 \mathrm{~min}$ at $4{ }^{\circ} \mathrm{C}$. Obtained serums were dispensed into micro tubes and stored at $-80^{\circ} \mathrm{C}$ until the measurement of blood parameters. For measuring plasma blood markers, blood samples collected into tubes containing ethylene diamine tetra acetic acid (EDTA) were immediately centrifuged and stored at $-80^{\circ} \mathrm{C}$ until the assay.

Blood glucose levels were measured by glucose oxidase method and fat levels were measured by standard enzymatic method using Kobas Mira model biochemical autoanalysis device.

\section{How to calculate body fat percentage}

The body fat percentage of the subjects was calculated using the German-made OMRON BF500 body composition.

\section{How to calculate caloric intake}

Subjects were recorded daily food intake on the note sheet and food consumed at breakfast, snack, lunch and dinner was calculated by N4 software.

\section{Statistical analysis}


Data were presented as mean \pm SD. The Kolmogorov-Smirnov test was used to check for normality of distribution of all blood parameters. The distribution of these parameters did not differ significantly from normal.

Independent t-test and dependent t-test were used to evaluate changes. Pearson correlation test was used to examine the relationship between the dependent variables (Pख0.05). Statistical significance was set at $P<0.05$. Data analysis was performed using SPSS version 18 software.

\section{Results}

In Table 1, the intra-group comparison of metabolic syndrome Index, weight, fat percentage, BMI and anxiety of EM and CM groups were noted. The results of paired T-test showed a significant effect of 12 months aerobic exercise on reducing blood pressure, triglyceride, waist circumference, BMI, weight, body fat percentage and anxiety (Table 1 ). 
Table 1

) values of methabolic syndrome indexies, wheight, BMI, and Body fat comparing intergra group of EM and $\mathrm{CM}$

\begin{tabular}{|c|c|c|c|c|c|}
\hline \multicolumn{4}{|l|}{ Group } & \multirow[t]{2}{*}{ Time Measurment } & \multirow[t]{2}{*}{ Index } \\
\hline Sig & $\mathrm{CM}$ & Sig & EM & & \\
\hline \multirow[t]{2}{*}{567.0} & $63.05 \pm 26.161$ & \multirow[t]{2}{*}{008.0} & $.3207 \pm 37.158$ & Pre-test & \multirow[t]{2}{*}{$\mathrm{SBP}(\mathrm{mmHg})$} \\
\hline & $58.07 \pm 87.159$ & & $.713 \pm 43.121$ & After 12 months & \\
\hline \multirow[t]{2}{*}{832.0} & $84.04 \pm 98.103$ & \multirow[t]{2}{*}{003.0} & $.3205 \pm 78.104$ & Pre-test & \multirow[t]{2}{*}{ Waist circumferents $(\mathrm{cm})$} \\
\hline & $75.05 \pm 21.104$ & & $.6103 \pm 52.93$ & After 12 months & \\
\hline \multirow[t]{2}{*}{378.0} & $27.42 \pm 58.174$ & \multirow[t]{2}{*}{005.0} & $65.32 \pm 84.182$ & Pre-test & \multirow[t]{2}{*}{ Glucose $(\mathrm{mg} / \mathrm{dl})$} \\
\hline & $03.64 \pm 98.170$ & & $.7310 \pm 63.115$ & After 12 months & \\
\hline \multirow[t]{2}{*}{238.0} & $53.45 \pm 08.264$ & \multirow[t]{2}{*}{001.0} & $34.74 \pm 32.256$ & Pre-test & \multirow[t]{2}{*}{ Triglyceride $(\mathrm{mg} / \mathrm{dl})$} \\
\hline & $74.68 \pm 87.260$ & & $23.12 \pm 84.143$ & After 12 months & \\
\hline \multirow[t]{2}{*}{074.0} & $46.04 \pm 23.45$ & \multirow[t]{2}{*}{327.0} & $45.12 \pm 36.41$ & Pre-test & \multirow[t]{2}{*}{ HDL (mg/dl) } \\
\hline & $84.06 \pm 64.46$ & & $82.04 \pm 47.53$ & After 12 months & \\
\hline \multirow[t]{2}{*}{427.0} & $38.05 \pm 49.34$ & \multirow[t]{2}{*}{000.0} & $54.04 \pm 63.33$ & Pre-test & \multirow[t]{2}{*}{ BMI (kg.m-2) } \\
\hline & $35.08 \pm 32.34$ & & $62.03 \pm 43.27$ & After 12 months & \\
\hline \multirow[t]{2}{*}{341.0} & $73.07 \pm 08.79$ & \multirow[t]{2}{*}{000.0} & $43.06 \pm 04.80$ & Pre-test & \multirow[t]{2}{*}{ Weight (kg) } \\
\hline & $68.09 \pm 88.80$ & & $04.04 \pm 83.70$ & After 12 months & \\
\hline \multirow[t]{2}{*}{742.0} & $89.07 \pm 87.37$ & \multirow[t]{2}{*}{000.0} & $34.08 \pm 56.36$ & Pre-test & \multirow[t]{2}{*}{ Body fat (\%) } \\
\hline & $97.09 \pm 76.38$ & & $72.04 \pm 42.28$ & After 12 months & \\
\hline \multirow[t]{2}{*}{253.0} & $33.06 \pm 25.25$ & \multirow[t]{2}{*}{000.0} & $76.05 \pm 64.24$ & Pre-test & \multirow[t]{2}{*}{ Anexiety } \\
\hline & $91.07 \pm 78.24$ & & $24.06 \pm 84.09$ & After 12 months & \\
\hline
\end{tabular}

The subjects of my group participated in 12 months of exercise with adherence to $91 \%$ in the study. According to both groups, in terms of total calorie intake, calorie intake of protein, carbohydrate and fat, fat percentage and body mass index were homogeneous, although no significant difference was observed in independent T-test results, so we did not consider any of the variables as a confounding variable (Table 2). 
Table 2

) Results of comparing the pre-test nutrition indecis among tested two syndrome groups of metabolic exprecise and metabolic control

\begin{tabular}{|llllll|}
\hline \multirow{2}{*}{ Sig } & \multicolumn{2}{l}{ Leven's Test } & CM & EM & \\
\cline { 2 - 5 } & Sig & F & & & \\
\hline 307.0 & 476.0 & 153.0 & $28.437 \pm$ & $54.287 \pm$ & Total calorie intake \\
& & & 98.2654 & 43.2754 & \\
\hline 702.0 & 532.0 & 167.0 & $23.70 \pm 65.545$ & $48.89 \pm 60.523$ & Total calories intake from protein \\
\hline 165.0 & 389.0 & 712.0 & $33.71 \pm$ & $27.74 \pm$ & Total calories intake from \\
\hline 734.0 & 568.0 & 023.0 & $31.55 \pm 22.815$ & $98.49 \pm 56.906$ & Total calories intake from fat \\
\hline 471.0 & 674.0 & 001.0 & $89.07 \pm 87.37$ & $34.08 \pm 56.36$ & fat percentage \\
\hline 566.0 & 365.0 & 024.0 & $38.05 \pm 49.34$ & $54.04 \pm 63.33$ & BMI \\
\hline
\end{tabular}

Table 3

) Comparison between the levels of anexity in-group after 12-months

\begin{tabular}{|llll|}
\hline Sig & CM & EM & \\
\hline 007.0 & $58.07 \pm 87.159$ & $71.3 \pm 43.121$ & SBP $(\mathrm{mmHg})$ \\
\hline 000.0 & $75.05 \pm 21.104$ & $61.03 \pm 52.93$ & Waist circumferents $(\mathrm{cm})$ \\
\hline 746.0 & $03.64 \pm 98.170$ & $73.10 \pm 63.115$ & Glucose $(\mathrm{mg} / \mathrm{dl})$ \\
\hline 000.0 & $74.68 \pm 87.260$ & $23.12 \pm 84.143$ & Triglyceride $(\mathrm{mg} / \mathrm{dl})$ \\
\hline 003.0 & $84.06 \pm 64.46$ & $82.04 \pm 47.53$ & HDL $(\mathrm{mg} / \mathrm{dl})$ \\
\hline 000.0 & $35.08 \pm 32.34$ & $62.03 \pm 43.27$ & BMI $\left(\mathrm{kg} . \mathrm{m}^{2}\right)$ \\
\hline 000.0 & $68.09 \pm 88.80$ & $04.04 \pm 83.70$ & Weight $(\mathrm{kg})$ \\
\hline 000.0 & $97.09 \pm 76.38$ & $72.04 \pm 42.28$ & Body fat $(\%)$ \\
\hline 000.0 & $91.07 \pm 78.24$ & $24.06 \pm 84.09$ & Anexiety \\
\hline BMI, Body Mass Index; SBP, Systolic Blood Pressure; HDL, High-density lipoprotein \\
\hline
\end{tabular}

The results of independent T-Test showed that there is a significant difference in the level of anxiety in the trained group compared to the control group, which is statistically significant.There is a significant correlation between anxiety/blood pressure, waist circumference and glucose (Table 4). 
Table 4

) The result of Pearson correlation coefficient

\begin{tabular}{|llllll|}
\hline HDL & Glucose & Triglyceride & Waist circumferents & SBP & \\
\hline 654.0 & $538.0-$ & $845.0-$ & $548.0-$ & $763.0-$ & Correlation of anxiety with \\
\hline 009.0 & 025.0 & 000.0 & 000.0 & 005.0 & Sig \\
\hline
\end{tabular}

\section{Discussion}

The American Diabetes Association recommended the intensity and duration of physical activity in this study in 2002, which recommended aerobic exercise with a intensity of 50 to $80 \%$ of the maximum aerobic power in three to four weeks (19). Based on the findings, anxiety was significantly reduced after 12 months of aerobic exercise ( $P \otimes 0.05)$. The correlation of anxiety with blood pressure, waist circumference and glucose was positive and significant $(P \otimes 0.05)$.

The results of the investigation of Smits et al. (2008), Broman et al. (2008), Andreas et al. (1998), Kargarfard et al. (2011), Salehpour et al. (2015) and Salehpoor et al. (2015) were consistent whith the result of present research (13-15,20-22). Considering that several fundamental studies have pointed out the relationship between anxiety and metabolic syndrome $(8-10,12) 6$ none of the existing research has the effect of aerobic exercise on anxiety and metabolic syndrome. For example, Smits et al. (2008) pointed out that exercise with a intensity of $70-90 \%$ of the maximum heart rate for 20 minutes and three times per week significantly reduces anxiety (20). Also Broman et al. (2008) had reported 20 minutes of exercise was effective in reducing anxiety in people who had more anxiety intensity than 28 (21). Andreas and associates (1998) reported 10 weeks of aerobic training effective in reducing severe anxiety (22). Kargarfard and associates (2011) examined the effect of eight weeks of training on the anxiety of hemophilia patients (13). Salehpoor et al. (2015) examined the effect of training on the anxiety of young people who had mental disorders (14). Also Sardari et al. (1388) investigated the effect of 8 weeks of aerobic training on anxiety in patients with type 2 diabetes (15). Considering that there is still no precise mechanism regarding the effects of exercise in improving anxiety, it is likely that the cause of anxiety reduction in the impact of exercise on the development of overall health and fitness and increasing social relationships of individuals $(13,15,20-22)$.

The causes of anxiety seem to be different at every stage of life. Martyr wives early due to stress and anxiety caused by social issues and concerns for the success of the children suffered alone. It can be said that the cause of metabolic syndrome is related to chronic anxiety of martyr's wives. Given that at this stage in the life of all the offspring are in good working and social positions, the cause of stress and anxiety of their can no longer be related to it. Most likely, the metabolic syndrome and the relative lack of health are the cause of anxiety for martyr's wives. Due to the increasing level of knowledge and awareness of the type of disease and their importance in anxiety, we can mention metabolic syndrome as the cause of current anxiety of martyr's wives. Aerobic exercise for 12 months with moderate intensity 
significantly reduced blood glucose, blood pressure, waist circumference, triglyceride, body fat percentage and BMI of 50-65 year old martyrs' wives. Reduced Blood glucose, blood pressure, waist circumference, triglyceride, body fat percentage, and BMI were significantly associated with reduced anxiety. On the other hand, increased endorphin secretion through regular exercise, which has a positive effect on relief, relaxation and happiness, may be one of the reasons for decreased anxiety.

\section{Conclusions}

improvement of metabolic syndrome after 12 months of moderate intensity exercise, they can be attributed to the reduction of anxiety and it can be suggested that aerobic exercises as a non-invasive strategy in the treatment of anxiety in women aged $65-50$ years with metabolic syndrome.

\section{Abbreviations}

AT

Aerobic Exercise Training

$\mathrm{CM}$

Metabolic Syndrome Control

EM

Metabolic Syndrome exercise

MetS

Metabolic Syndrome

SBP

systolic blood pressure

\section{Declarations}

\section{Ethics approval and consent to participate}

Bonab University Review Board for the protection of human subjects (Approval date, 2018-July-17) approved this study.

\section{Consent for publication}

All participants were aware during the informed consent process that the results of this study may be published.

\section{Competing interests}

The authors declare that they have no competing interests.

\section{Publisher's Note}


Springer Nature remains neutral with regard to jurisdictional claims in published maps and institutional affiliations.

\section{Contributions}

The study was designed by OA; data were collected and analyzed by OA; data interpretation and manuscript preparation were undertaken by $\mathrm{OA}$.

\section{Acknowledgements}

We thank to all the subjects who volunteerly participated and we also gratefaly thank dear president of Martyr Foundation and Sacrifice Affairs who sincerely helped us in this research.

\section{Affiliations}

Ali Osali

Exercise physiology, physical education and sport sciences, University of Bonab, Bonab, Iran Corresponding Author: Osali A, Department General Courses, University of Bonab, Bonab, Iran E-mail: osalialiphd@gmail.com

Availability of data and materials not applicable. Conclusions of the manuscript are based on relevant data sets available in the manuscript.

\section{References}

1. Alipour F, Sajadi H, Forouzan A, Biglarian A, Jalilian A. Quality of life in elderly region 2 Tehran. Iranian journal of ageing [in Persian]. 2008;3(10):75-83.

2. Sharifzadeh GH, Moudi M, Akhbari S.H. Investigating health status of older people supported by imam Khomeini. Iranian journal of ageing. 2010;3(7):52-60.

3. Sérgio Gomes da Silva, Priscila Santos Rodrigues Simões, Renato Arruda Mortara, Fulvio Alexandre Scorza, Esper Abrão Cavalheiro, Maria da Graça Naffah-Mazzacoratti, et al. Exercise-induced hippocampal anti-inflammatory response in aged rats. Neuroinflammation. 2013;10:61.

4. Cavalieri M, Ropele S, Petrovic K, Pluta-Fuerst A, Homayoon N, Enzinger C, et al. Metabolic syndrome, brain magnetic resonance imaging, and cognition. Diabetes Care. 2010;33(12):2489-95.

5. Grundy SM, Cleeman JI, Daniels SR, Donato KA, Eckel RH, Franklin BA, et al. Diagnosis and management of the metabolic syndrome: an American heart association/national heart, lung, and blood institute scientific statement. Circulation. 2005;112:2735-52. 
6. Aline Sardinha, Antonio E Nardi. The Role of Anxiety in Metabolic Syndrome. Endocrinol Metab. 2012;7(1):63-71.

7. Arce M, Michopoulos V, Shepard KN, Ha QC, Wilson ME. Diet choice, cortisol reactivity, and emotional feeding in socially housed rhesus monkeys. Physiol Behav. 2010;101(4):446-55.

8. Carroll D, A. C. Phillips, G. N. Thomas, C. R. Gale, I. Deary, G. D. Batty. Generalized anxiety disorder is associated with metabolic syndrome in the Vietnam experience study. Biol Psychiatry. 2009;66:91-3.

9. Kai G. Kahl, Ulrich Schweiger, Christoph Correll, Conrad M€uller, Marie-Luise Busch, Michael Bauer, et al. Depression, anxiety disorders, and metabolic syndrome in a population at risk for type 2 diabetes mellitus. Brain and Behavior. 2015;5(3):1-7.

10. van Reedt Dortland, A. K, E. J. Giltay, T. van Veen, F. G. Zitman, B. W. Penninx. Metabolic syndrome abnormalities are associated with severity of anxiety and depression and with tricyclic antidepressant use. Acta Psychiatr Scand. 2010;122:30-9.

11. Takeuchi T, Nakao M, Nomura K YE. Association of metabolic syndrome with depression and anxiety in Japanese men. Diabetes Metab. 2009 35(1):32-6.

12. Nicole Vogelzangs, Aartjan T. F. Beekman, Stephen B. Kritchevsky, Anne B. Newman, Marco Pahor, Kristine Yaffe, et al. Psychosocial risk factors and the metabolic syndrome in elderly persons: findings from the health, aging and body composition study. J Gerontol. 2007;62(5):563-9.

13. Mehdi Kargarfard, Mehdi Dehghani, Heidari A. Effect of a period of aquatic exercise therapy on the quality of life, anxiety and depression in patients with hemophilia. koomesh. 2011;4:364-72.

14. Masoomeh Salehpoor, Mohsen Salesi, Ghorban Hemati Alamdarloo. The Effect of Exercise on Anxiety of Adolescents with Intellectual Disability. physical treatments. 2015;5(1):25-32.

15. Sardar M, Sohrabi M, Shamsian A, Aminzadeh R. Effects of Aerobic Exercise training on the Mental and Physical Health and Social Functioning of Patients with Type 2 Diabetes Mellitus. Iranian Journal of Endocrinology and Metabolism. 2009;11(3):251-6.

16. Babaei P, damirchi A, Azali Alamdari K. Effects of Endurance Training and Detraining on Serum BDNF and Memory Performance in Middle Aged Males with Metabolic Syndrome. Iranian Journal of Endocrinology and Metabolism. 2013;15(2):132-42.

17. Patanella AK, Zinno M, Quaranta D, Nociti V, Frisullo G, Gainotti G, et al. Correlations Between Peripheral Blood Mononuclear Cell Production of BDNF, TNF-alpha, IL-6, IL-10 and Cognitive Performances in Multiple Sclerosis Patients. Journal of Neuroscience Research. 2010;88:1106-12.

18. Qi Z, He J, Zhang Y, Shao Y, Ding S. Exercise training attenuates oxidative stress and decreases p53 protein content in skeletal muscle of type 2 diabetic Goto-Kakizaki rats. Free Radic Biol Med. 
2011;50(7):794-800.

19. ADA. Diagnosis and classification of diabetes mellitus. Diabetes. 2004;27(1):5-10.

20. Smits JAJ, Berry AC, Rosenfield D, Powers MB, Behar E, Otto MW. Reducing anxiety sensitivity with exercise. Depression and Anxiety. 2008;25:689-99.

21. Broman-Fulks JJ, Storey KM. Evaluation of a brief aerobic exercise intervention for high anxiety sensitivity. Anxiety Stress Coping 2008;21:117-28.

22. Andreas Broocks, Borwin Bandelow, Gunda Pekrun, Annette George, Tim Meyer, Uwe Bartmann, et al. Comparison of Aerobic Exercise, Clomipramine, and Placebo in the Treatment of Panic Disorder. Am J Psychiatry. 1998;155:603-9.

23. Osali A, Kordi M, Azad A. The Effects of Carbohydrates and Branched Chain Amino Acid Supplements Consumption in Recovery Period on Secretion of Insulin and Preserving the Performance of Wrestlers. journal of sport biosciences. 2009;1(2):129-272.

24. Davis JM, S.P. Bailey, J.A.Woods, F.J. Galiano, M.T. Hamilton, Bartoli WP. Effects of carbohydrate feedings on plasma free tryptophan and branched-chain amino acids during prolonged cycling. . European Journal of applied and Occupational Physiology. 1992;65:513-9.

25. Blomstrand E. Amino acids and central fatigue. Amino Acids J Physiol Endocrinol Metab. 2001;20(1):25-34.

26. Zorilla EP LL, McKay JR, Roesnthal R, Houldin A, Tax A, et al. . The relationship of depression and stressors to immunological assays: A meta-analytic review. Brain Behav Immun. 2001;15:199-226.

27. Mossner R MO, Koutsilieri E, Saoud M, Ehlis AC, Muller N, et al. Consensus paper of the WFSBP Task Force on Biological Markers: Biological markers in depression. World J Biol Psychiatry. 2007;8:141-74. 